\title{
A GENERALIZATION OF HYERS-ULAM-RASSIAS STABILITY OF THE G-FUNCTIONAL EQUATION
}

\author{
GWANG HUI KIM
}

Abstract. We investigate a generalization of the Hyers-Ulam-Rassias stability for the gamma type functional equation $f(x+p)=\Gamma(x) f(x)+\psi(x)$ and the stability in the sense of Ger for the functional equation of the form $f(x+p)=\Gamma(x) f(x)$. As a consequence, we obtain a stability result in the sense of Hyers-Ulam-Rassias for $G$-functional type equations.

Mathematics subject classification (2000): 39B52, 39B72, $39 \mathrm{~B} 82$.

Key words and phrases: functional equation, gamma and beta function, Hyers-Ulam stability, HyersUlam-Rassias stability, $p$-series.

\section{REFERENCES}

[1] H. AlzER, Remark on the stability of the Gamma functional equation, Result. Math., 35, (1999), 199-200.

[2] E. W. BARNES, The theory of the G-function, Quart. J. Math., 31, (1899), 264-314.

[3] P. GǍVRUTA, A Generalization of the Hyers-Ulam-Rassias stability of approximately additive mappings, J. Math. Anal. Appl., 184, (1994), 431-436.

[4] R. GER, Superstability is not natural, Roczik Naukowo-Dydaktyczny WSP w Krakowie, Prace Mat., 159, (1993), 109-123.

[5] D. H. HYERS, On the stability of the linear functional equation, Proc. Nat. Acad. Sci. U. S. A., 27, (1941), 222-224.

[6] D. H. Hyers, G. IsAC AND TH. M. RAssias, Stability of the Functional Equations in Several Variables, Birkhäuser Verlag, 1998.

[7] K. W. Jun, G. H. Kim AND Y. W. LEE, Stability of generalized Gamma and Beta functional equations, Aequationes Math., 60, (2000), 15-24.

[8] S. M. JUNG, On the general Hyers-Ulam stability of gamma functional equation, Bull. Korean Math. Soc., 34, (1997), 437-446.

[9] S. M. JunG, On the modified Hyers-Ulam-Rassias stability of the functional equation for gamma function, Mathematica, Cluj, 39, (1997), 233-237.

[10] S. M. JunG, On the stability of gamma functional equation, Results in Math., 33, (1998), 306-309.

[11] G. H. KIM, On the stability of generalized Gamma functional equation, Internat. J. Math. \& Math. Sci., 23, (2000), 513-520.

[12] G. H. KIM, The stability of generalized Gamma functional equation, Nonlinear Studies, 1, (2000), 92-96.

[13] G. H. KIM, A generalization of the Hyers-Ulam-Rassias stability of the Beta functional equation, Publ. Math. Debrecen, 59, (2001), 111-119.

[14] G. H. KIM, Stability of the G-functional equation, Korean J. Comput. \& Appl. Math.(Series A), 9, (2002), 837-844.

[15] G. H. KIM, Y. W. LEE, The stability of the beta functional equation, Studia Univ. "Babes-Bolyai", Mathematica, 40, (2000), 89-96.

[16] TH. M. RASSIAS, On the stability of the linear mapping in Banach spaces, Proc. Amer. Math. Soc., 72 , (1978), 297-300. 
[17] TH. M. RASSIAS, P. ŠEMRL, On the behavior of mappings which do not satisfy Hyers-Ulam stability, Proc. Amer. Math. Soc., 114, (1992), 989-993.

[18] TH. M. RASSIAS, J. TABOR, Stability of Mappings of Hyers-Ulam Type, Hadronic Press Inc., Florida, 1994.

[19] S. M. Ulam, Problems in Modern Mathematics Chap. VI, Science editions, Wiley, New York, 1964. 